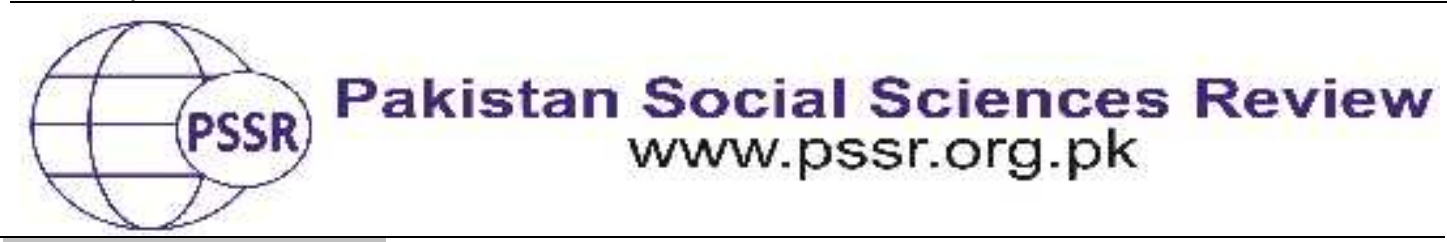

RESEARCH PAPER

\title{
The Pandemic COVID-19: Impacts on Sports Economy
}

\author{
Mehwish Manzoor*1 Sairh Jabeen ${ }^{2}$ ReemaAman ${ }^{3}$
}

1. Visiting Lecturer Department of Physical Education, University of Narowal, Punjab, Pakistan

2. Gomal University, KPK, Pakistan

3. Lecturer, Department of Sports Science, University of Sargodha, Punjab, Pakistan

\begin{tabular}{|c|c|}
\hline PAP & ISD \\
\hline $\operatorname{Rec}$ & in wor \\
\hline & \\
\hline & ar, the \\
\hline & Antarctica. \\
\hline & Becau \\
\hline $\begin{array}{l}\text { Key } \\
\text { Cov } \\
\text { Mea } \\
\text { Pan } \\
\text { Spo }\end{array}$ & $\begin{array}{l}\text { day, sports workers are mislaying occupation and ear } \\
\text { no way of knowing when normality will re } \\
\text { international labor organization estimates that } 1\end{array}$ \\
\hline${ }^{*} \mathrm{Cc}$ & 800 million \\
\hline & demic has reached the economy of the world \\
\hline Teh & e. \\
\hline
\end{tabular}

\section{Introduction}

Covid-19 is a virus reasoned via a stress of coronavirus. "CO" means corona, "VI" for virus, then "D" for disease. Earlier, virus has mention toward in"2019 story coronavirus" else "2019-nCov". COVID-19 disease is a new virus connected to the same issues family of diseases as critical serious respiratory disorder \& approximately kinds of virus infection of the respiratory tract. The pandemic has reach the economy of the world very difficult and sports are no exclusion. The economic organization of sports is as well as to change, with below ranks nationwide facing a crisis in financial sum (Andrade, 2019).

The worldwide economic crisis initiate via covid-19 virus is able modification including sports manufacturing in direction of concept unimaginable until nowadays. Some sports will be reach very difficult than others. The economic organization of sports is possible to modification and below rank nationwide faces a 
crisis of financial sum. The research study not throws light on the effects of pandemic covid-19 on the sports world but also describe the organizing \& sanative scale to defeated the circumstance (WHO, 2019)

An extensive geographic places and affecting an extremely high percentage of the population. An epidemic of a disease that arises above an extensive topographical region and upsets an extremely high quantity of the population a disease epidemic of a virus. Coronavirus disease 2019 is actually an acute lung disease caused by a virus and described by fever, coughing, and shortness of breath

Sport training has an influential means adoptive physical ability, intellectual wellness, as well societal and behavior where as people has shutdown.

Physical movements Activity and Game, the Excellence Physical activity Strategy Package, and the Standards Education over and done with Sport items endure extremely significant refers to confirm and various virtual physical movements, physical exercises elements and also being presently arranged meet the terms with gender equivalence, non-discrimination, protection, and excellence, values (Huang, 2020).

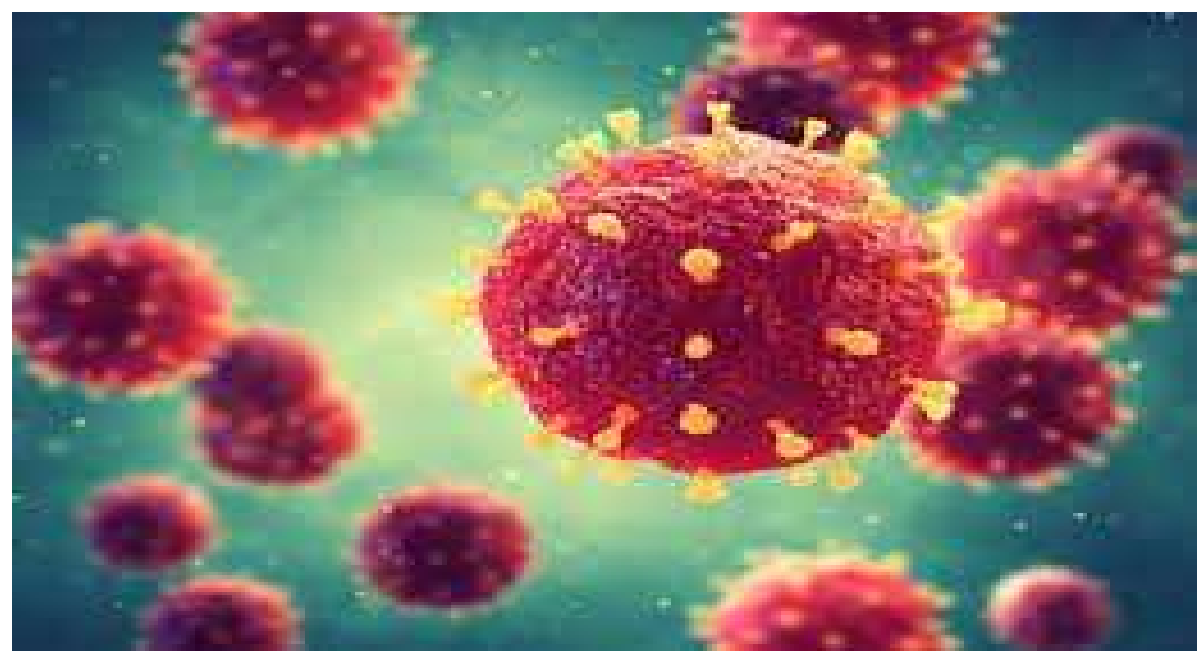

Most important events in the sports world have been hit very hard hampering the sports economy to the maximum. As a result of which the major sports competitions are postponed. Few major competitions postponed are listed below:

- Tokyo Olympic Games suspended will present day, start arranged in 23 July, 2021, and path till $8^{\text {th }}$ August.

- Athletics world was postponed Olympic requirement until to December.

- The suspended Paralympics Sports will track from 24 August-5 September, 2021.

- Main Association football will resume the period on 8 July, performance an event at Disney World in Orlando, Florida. 
- In 2020 and Copa America has suspended. The 2eventsnowadays be performed from 11 June to 11 July, 2021.

- 2021 euro Women's Competition takes hard upto6 July-31, 2022.

- The women's Under-20 World Cup in Costa Rica and Panama, postponed from August-September, has been postponed for January 20-February 6, 2021.

- The World Athletics Indoor Competitions (Nanjing, March 13-15) were suspended to March 19-21, 2021.

- Thomas and Uber Cup will be held to 3-11 October, T-20 world Cricket Competition.

- This time's Multi-Sport Global Level Competitions, and a specific to time held in Almere from September 4-13, have been strapped back to 2021. The 2021 event in Townsville will passage to 2022, while Ibiza will host the events in 2023.

- The 2021 World Championships will start in late November instead of August to avoid conflicting with the postponed Olympics in Tokyo.

- Cycling that was due to be held tour de France from 27 June 19-July was suspended to August 29- September 2020.

- Industries of sports goods and services are running in loss due to COVID-19 specially in Sialkot Pakistan. Sports industries are suffering due to COVID-19 and current account deficit is at its top of pyramid in loss.

\section{Literature Review}

\section{Sports and Covid-19}

Huang,(2020), the COVID-19 virus describing worldwide well-being \& fitness disaster of our period then the extreme challenge we have challenged since world $2^{\text {nd }}$ combat. Then it has occurred in Asia previous time, this disease has quickly to each continent excluding Antarctica. Because, this epidemic situation has plentiful further than wellness, well-being and fitness crunch; and too an unparalleled socioeconomically crunch. Each time of days, our working population is dropping occupations and earnings, with no technique of perceptive while routine will return. And employment international association estimations maximum 195 million occupations might be missing. The World Bank schemes as below billion decay in settlement this years, this which might 800 million societies has not be capable to chance their essentials desires. The virus has sensation the budget of the world very unbreakable and sports are no exclusion. The economic organization of sports is expected to modification, with below rank nationwide facing a fund crunch. Below current sports and indigenous sports are staring at an indefinite upcoming time. Athlete, trainers, and coaches are having the hardest time of their professions. The worldwide economic crash caused via COVID-19 disease might adjustment the whole sports manufacturing in systems assumed impossible until now. Approximately sports will be sensation tougher than others. Economical organization of sports is expected to modification minor rank nation-states will facing a crisis in resources. 


\section{Effect of Covid-19 on Sports Economy}

\section{Effect on the Sports Industry}

Zhao(2020), define the world is appearing the improvement of coronavirus (COVID-19) and its consequence on a worldwide measure. The impact of COVID-19, which is already measured a worldwide epidemic by the World Health Organization, are getting thousands of cases in every part of the world and will cause heartless economic loss. The harmful economic consequence of the pandemic and its recessive responses fearful the financial market. The economic damages will be gigantic, and the stock markets dissolve daily around the world because of it. We too have the Tokyo Olympic Games, the largest event on the world, which at this period of time has not the slightest situation to be held. The UEFA EURO Championship has already been suspended from 2020 till 2021. Furthermore, sports, as a significant economic zone, are also suffering powerfully as well. We are looking competitions being postponed or extended.

According to economically rate, However, Sialkot, Pakistan is known for industrial and export of many items such as surgical apparatuses, musical apparatuses, sports goods and leather goods. Sialkot, Pakistan is the second largest source of foreign exchange incomes for Pakistan because of its exports' and remittance from foreign manpower. The "Forward sports" industry was made by FIFA football world cup's, a company founded in Sialkot, Pakistan. Sialkot's hand stitch footballs are popular worldwide for their excellent value.

Industries of sports equipment and services are running in loss due to COVID-19 especially in Sialkot Pakistan. Sports industries are suffering due to COVID-19 and current account deficit is at its top of pyramid in loss.

\section{Effect on Sports Organizations}

The effect of the covid-19disaster has various depend on the zone that examine of our sports world. In expert sports, anywhere we talk about largest stadiums, television rights, supporters, etc., where there surely is an important capacity of professional in situations of earnings and a change of these earnings by many agents, the effect is going to be important, but it may be manageable up to a certain point. The main source of income for professional sports is frequently from television rights, which are found on an agreement with solid lawful situations cautiously reviewed by specialists. However, an insurance section cover covid-19 is involved in this agreement and may protection a good part of the calculation or estimation of earnings the clubs have, in this situation. Confidently, the concluding effect cannot be expected exact nowadays because, it is now uncertain, if sports events are going has to with the organization \& estimate that exist when the schedule has make get ready at the start of the season. However, if can be carry out, the impact is observably successful to be, from the point of view of technical and occupational sport and in economic feature, the effect better to be maximum zero. At 
the finally research, and prepared to implementation, and transmission of these matches will finish up happening. However, in skill full and occupational sports professionals, the economical influence, for the movement, is estimated to be limited.

\section{Effect on Schools and Colleges}

Sports colleges are senior secondary school which promotes sports alongside secondary education. University game makes approximately 1 billion every year in ticket sales and advancements for universities, according to the National Collegiate Athletic Association (NCAA). The Athletic dollars from basketball, football, and volleyball can donate more than half to a school's functioning financial plan. "There's never a good time for an epidemic but for college sports, I think this was particularly bad, because it ensued accurate at the establishment of the men's basketball competition.

\section{Effect on Fitness Industries}

Shereen (2020), the warning of corona disease has left the health fitness manufacturing such as fitness center, yoga, and aerobic center sailing and scarcely competent to position with small gymnasiums on the limit of lock down, biggest chains considering gigantic loss in this current situation, and job loss attractive an actual scene for more thousands of many coaches\& administrative workers. And hardly a week then gymnasiums through the nation state lockdown markets and the industries is putrefying above the stress of the coronavirus epidemic, said insiders. They epidemic has directed to a shutdown in more portions of the nation state has reach centers for health fitness large and minor - however neighborhood gymnasiums, by the maybe a couples of routines and a cross instructor or 2, or countrywide chains such as Gold Gymnasium and Cult fit that take at minimum 30 centers in city alone. Gym owners said that their industries are painful loss, influence them place to off workers in the short term.Figure: 1 shows that in this graph.

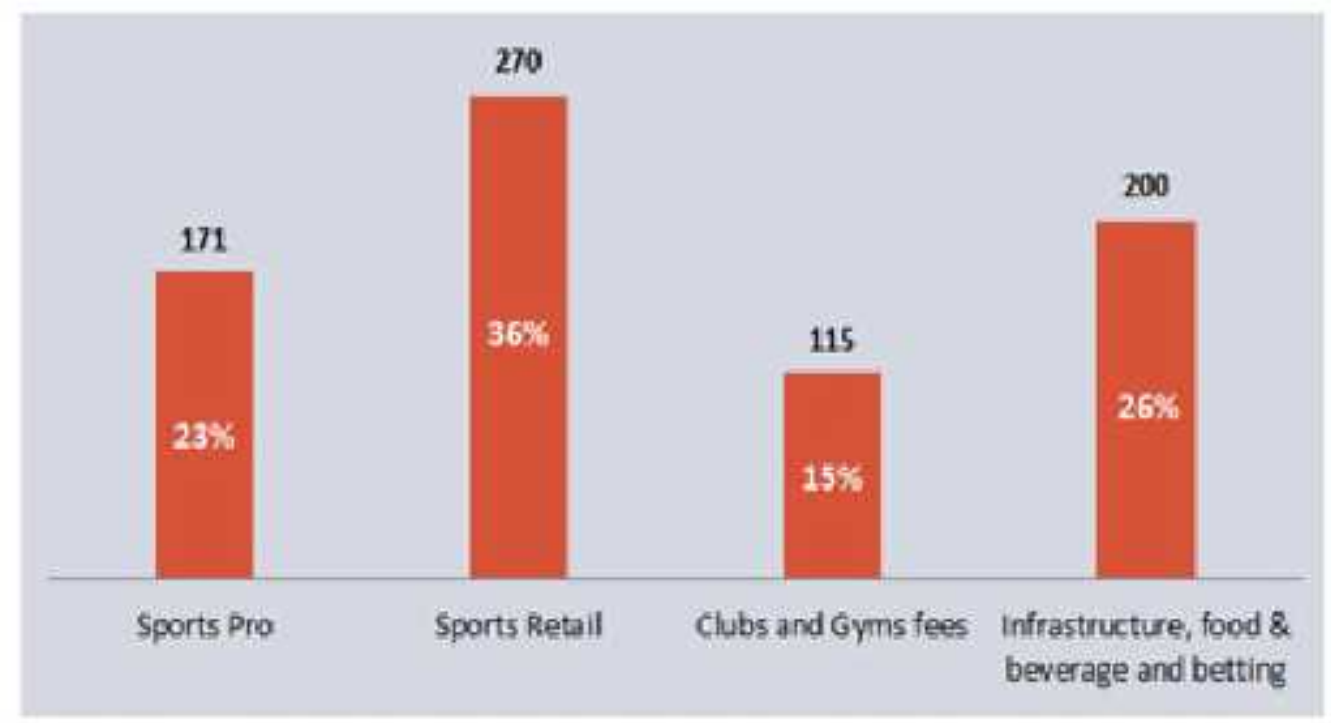




\section{Effect on the Sportsman}

Instructors and trainers across the world has been partaking concepts and advanced techniques to stay home and stay active. At the Youth Sport Selfconfidence, free-to-access "Home virtual Education" activities have been added daily - fascinating over 48,000 webpage appointments in the 1st week of lockdown. Maximum sportspersons, although, the largest risks to accomplishment will small to ensure with the disease herself. North, estimate that about the $50 \%$ of athletes on maximum schedules are managing with damage at any certain time. Nowadays, sports instructors adapted to every day contacts with to hold online meeting videoconference and daily motivational advises about daily physical activities and exercises.

\section{Material and Methods}

A major sample of video recording of certified players \& workers in Pakistan, and adopt online survey method, received the feedback to different players and sports workers were analyzed to way individually players' and manufacturing time of close body interaction and rate of infection-risky manners to examine the hazard of disease broadcast for the duration of event and one of the main cause is impact of sports economy.

To examine the biological effect of wearing a facemask during exercise, we conducted a measured laboratory, and many virtual techniques for physical movement, within-subject, repeated scale study of some healthy many sport athletic competition circumstances.

And sample of economic impact of covid-19 on sports workers, in our Sialkot Pakistan basically Sialkot have major area of nationwide.

\section{Results and Discussion}

Table 1 shows that the workers age wise 25-34 are most affected by shutdown in the world. Basically Age 14-18 number of employed percentage 8\%, Age 19-21 number of employed percentage 10\%, Age 22-24 number of employed percentage 9\%, Age 25-34 number of employed percentage 23\%, Age 35-44 number of employed percentage 16\%, Age 45-54 number of employed percentage 15\%, Age 55-64 number of employed percentage $12 \%$, Age $65+$ number of employed percentage $7 \%$. Basically the economic effect of COVID-19 on sports is very critical situation, especially in Sialkot Pakistan sports industries. In addition to it in table are given below.

Table 1

Economic effect of covid-19 on sports workers

\begin{tabular}{ccc}
\hline Age Range & Number Employed & \%of Total \\
\hline Age 14-18 & 150,333 & $8 \%$ \\
\hline Age 19-21 & 189,999 & $10 \%$ \\
\hline
\end{tabular}




\begin{tabular}{ccc}
\hline Age 22-24 & 175,156 & $9 \%$ \\
\hline Age 25-34 & 440,107 & $23 \%$ \\
\hline Age 35-44 & 322,060 & $16 \%$ \\
\hline Age 45-54 & 290,212 & $15 \%$ \\
\hline Age 55-64 & 239,675 & $12 \%$ \\
\hline Age 65+ & 136,588 & $7 \%$ \\
\hline
\end{tabular}

A fully lockdown is the previous item a manufacturing would always imagine to contract with. Circumstances becomes forbidding when processes are stalled at the ultimate of commercial period. Though all professional initiatives are reeling under the harm of chances and economic influence as the world has come to a standstill, sports equipment's industry in Pakistan is among the worst reach. The occupational is shut at a time when sports events and the occupational capacity success the peak. Sports fan's attitudes success the top in Pakistan. The element period and all over again is ascertained by broadcast listener's ratio and sports occupational information by highest surveyors. In March-April is the time when a new crop of aspiring sportspersons joins sports academies.

\section{Conclusion}

The COVID-19 epidemic has and will remain to have very sizeable impact not only on the honorable but also on the fitness \&mental and mental wellness of people everywhere the world. It is extremely recommended that the sporting events are renewed with extreme care as suggested by the world bodies to maximize the assistances this game and training activity/movement be able to array in the stage of coronavirus and further than.

Sport training is an influential means to stand-in physical fitness, intellectual wellness, as well as societal approaches and behavior although peoples are shutdown. Global rights and worth based sport training mechanisms and items, such as the Global Charter of Physical Activity and Sport, the Excellence Physical Activity Strategy Platform, then Standards of Education through Sport plans endure extremely applicable reference toward confirm that the bundles of virtual many classes about physical movement components.

\section{Recommendations}

- Repeatedly and systematically clean your hands with an alcoholic liquids based hand shower them with soap and water, basically covid-19 virus is very dangerous. Why? Washing your hands with soap and water or using malt based hand rub executes germs that may be on your hands.

- Minimum $1 \mathrm{~m}$ space among yourself and others. Why? When someone coughs, or communicates they spray small liquid droplets from their nose or mouth which may contain virus. If you are too close, you can breathe in the droplets, including the COVID-19 virus if the person has the disease. 
- The United Nations system, through its sports, strategy mechanisms and mechanisms such as the International Committee for Physical Education and Athletic as well as concluded its investigation and strategy supervision must maintenance governments and other participants to confirm in effect retrieval and the game sector and, at the similar time of period, support the use of game to reach supportable growth and peacetime.

- Ignore the touching eyes, nose, and mouth. Why? Hands touch many surfaces and can pick up viruses.

\section{Your Safety Is Our Top Priority We mre haking extra prechutions aghingt

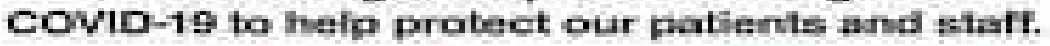

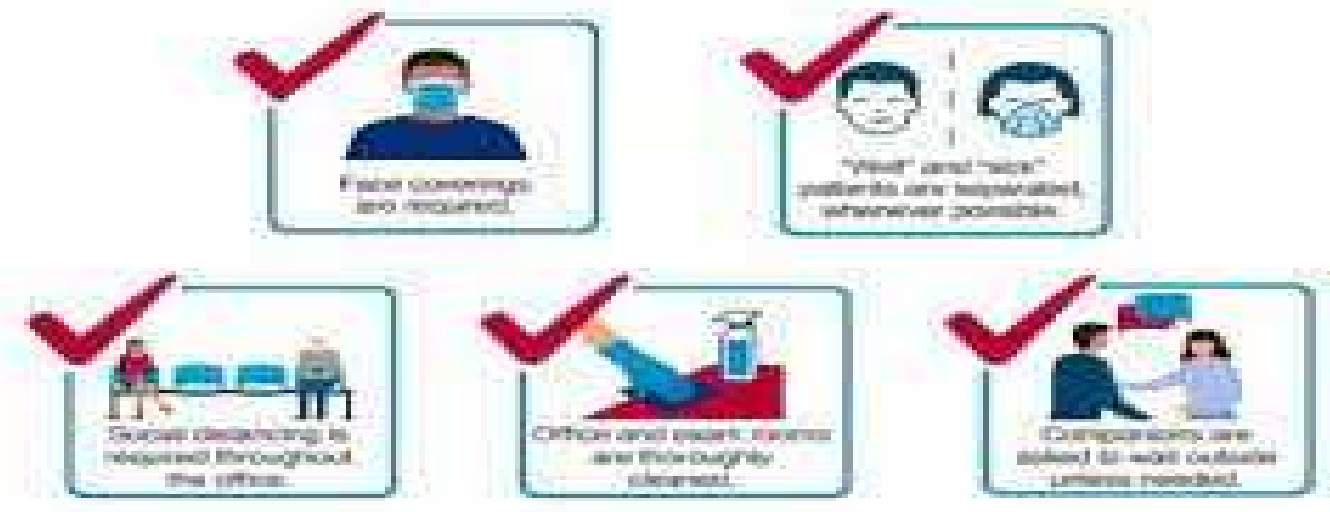

- Governments must effort collectively with our health fitness and carefulness facilities, schools, and administrations representative various social groups to maintenance physical activity at home. Though, below-tech and no-teaching solutions essential also be required for those who presently absence assist to the internet.

- Governments, the United Nations, and the evenhanded community, including the sporting education public, must broadcast WHO and other guidance on separate and joint measures to counter the epidemic. Methods essential be taken to reach communities that have limited admittance to the internet and social media. 


\section{References}

Andrade A, Dominski FH, Pereira ML, De Liz CM, \&Buonanno, G. (2019). Infection risk in gyms during physical exercise. Environ SciPollutRes ;25:19675-86.

Huang, Y. Wang, X. Li, (2020) .Clinical features of patients infected with 2019 novel coronavirus in Wuhan, China Lancet, 395 (10223), pp. 497-506, 10.1016/S01406736(20)30183-5

Shereen, A, S. Khan, A. Kazmi, N. Bashir, R. Siddiqu, (2020). COVID-19 infection: origin, transmission, and characteristics of human coronavirus, advance research J Adv 10.1016/j.jare,03.005

Mehta, P.McAuley, D. F. Brown, M. Sanchez, E. Tattersall, R. S, \& Manson, J, J. (2020). COVID-19: Consider cytokine storm syndromes and immunosuppression. Lancet, 395:1033-4.

Stephen F. (2020). RCS Sport Cancels StradeBianche in Light of Coronavirus Measures. Cyclingnews; Coronavirus: How The Virus Has Impacted Sporting Events Around The World. London: BBC; 2020. 9. How the Coronavirus is Affecting Sports Leagues and Events. Los Angeles Times

World Curling Federation,(2020). 2019-2020 Season Ends with Event Cancellations. World Curling Federation

Zhao, J. Li, (2020). Genomic characterisation and epidemiology of 2019 novel coronavirus: implications for virus origins and receptor binding Lancet, 395 (10224), pp. 565-574, 10.1016/S0140-6736(20)30251-8 